\title{
Agonist and antagonist effects of tobacco-related nitrosamines on human $\alpha 4 \beta 2$ nicotinic acetylcholine receptors
}

\author{
Simone Brusco, Paola Ambrosi, Simone Meneghini and Andrea Becchetti * \\ Department of Biotechnology and Biosciences, University of Milano-Bicocca, Milano, Italy
}

Regulation of the "neuronal" nicotinic acetylcholine receptors (nAChRs) is implicated in both tobacco addiction and smoking-dependent tumor promotion. Some of these effects are caused by the tobacco-derived $\mathrm{N}$-nitrosamines, which are carcinogenic compounds that avidly bind to nAChRs. However, the functional effects of these drugs on specific

OPEN ACCESS

Edited by:

Jean-François Desaphy, University of Bari Aldo Moro, Italy

Reviewed by:

David J. Adams, RMIT University, Australia

Hildegard M. Schuller, University of Tennessee, USA

*Correspondence:

Andrea Becchetti,

Department of Biotechnology and Biosciences, University of Milano-Bicocca, Piazza della Scienza,

2, 20126 Milano, Italy andrea.becchetti@unimib.it

Specialty section:

This article was submitted to Pharmacology of Ion Channels and Channelopathies,

a section of the journal

Frontiers in Pharmacology

Received: 26 July 2015 Accepted: 01 September 2015 Published: 22 September 2015

Citation:

Brusco S, Ambrosi P, Meneghini S and Becchetti A (2015) Agonist and antagonist effects of tobacco-related nitrosamines on human $\alpha 4 \beta 2$ nicotinic acetylcholine receptors.

Front. Pharmacol. 6:201.

doi: 10.3389/fphar.2015.00201 nAChR subtypes are largely unknown. By using patch-clamp methods, we tested 4-(methylnitrosamine)-1-(3-pyridyl)-1-butanone (NNK) and N'-nitrosonornicotine (NNN) on human $\alpha 4 \beta 2 \mathrm{nAChRs}$. These latter are widely distributed in the mammalian brain and are also frequently expressed outside the nervous system. NNK behaved as a partial agonist, with an apparent $\mathrm{EC}_{50}$ of $16.7 \mu \mathrm{M}$. At $100 \mu \mathrm{M}$, it activated $16 \%$ of the maximal current activated by nicotine. When NNK was co-applied with nicotine, it potentiated the currents elicited by nicotine concentrations $\leq 100 \mathrm{nM}$. At higher concentrations of nicotine, NNK always inhibited the $\alpha 4 \beta 2 \mathrm{nAChR}$. In contrast, NNN was a pure inhibitor of this $\mathrm{nAChR}$ subtype, with $\mathrm{IC}_{50}$ of approximately $1 \mathrm{nM}$ in the presence of $10 \mu \mathrm{M}$ nicotine. The effects of both NNK and NNN were mainly competitive and largely independent of $V_{m}$. The different actions of NNN and NNK must be taken into account when interpreting their biological effects in vitro and in vivo.

\section{Keywords: CHRNA4, CHRNB2, HEK, nAChR, NNK, NNN, partial agonist, patch-clamp}

\section{Introduction}

The nAChRs are ligand-gated ion channels permeable to cations, which regulate cell excitability and synaptic transmission. They are formed by different $\alpha$ and $\beta$ subunits, which assemble to form homo- or heteropentamers (Dani and Bertrand, 2007). The homopentameric receptors, such as the widespread $(\alpha 7)_{5}$, have low sensitivity to $\mathrm{ACh}$ and nicotine (with $\mathrm{EC}_{50}$ higher than $100 \mu \mathrm{M}$ ), high permeability to $\mathrm{Ca}^{2+}\left(\mathrm{P}_{\mathrm{Ca}}\right)$ and rapid desensitization. The heteromeric nAChRs generally display higher sensitivity to the agonists, lower $\mathrm{P}_{\mathrm{Ca}}$ and slower desensitization (Dani and Bertrand, 2007). The most common high-affinity form in the mammalian brain is the $\alpha 4 \beta 2 *$, with apparent $\mathrm{EC}_{50}$ values at least 10 times lower than those displayed by $(\alpha 7)_{5}$. In the peripheral nervous system,

Abbreviations: CNS, central nervous system; DH $\beta E$, dihydro- $\beta$-erythroidine; nAChR, neuronal nicotinic acetylcholine receptor; $\mathrm{EC}_{50 h i g h}$ and $\mathrm{EC}_{50 \mathrm{low}}, \mathrm{EC}_{50}$ values for two-term Hill equations; $\mathrm{HEK}$, human embryonic kidney; $\mathrm{n}_{\mathrm{H}}$, Hill coefficient for one-term Hill equation; $\mathrm{n}_{\mathrm{H} 1}, \mathrm{n}_{\mathrm{H} 2}$, Hill coefficients for two-term Hill equation; NNK, 4-(methylnitrosamine)-1-(3pyridyl)-1-butanone; $\mathrm{NNN}, \mathrm{N}^{\prime}$-nitrosonornicotine; $\mathrm{V}_{\mathrm{m}}$, membrane potential; $\mathrm{V}_{\text {rev }}$, reversal potential. 
the prevalent $\mathrm{nAChR}$ subtype is $\alpha 3 \beta 4$, which shows a more restricted expression in the CNS (Zoli et al., 2015). Nicotinic subunits are also widely expressed in other tissues, where their functions are still debated (Wessler and Kirkpatrick, 2008). In cancer cells, different types of homo- and heteromeric nAChRs cooperate in controlling several aspects of the neoplastic phenotype (Egleton et al., 2008; Schuller, 2009; Ambrosi and Becchetti, 2013; Schaal and Chellappan, 2014). Recently, the nAChR genes CHRNA3, CHRNA5, and CHRNB4 have been implicated in lung cancer susceptibility as well as nicotine addiction (Improgo et al., 2013, and references therein).

The complex pattern of $\mathrm{nAChR}$ expression may partly explain the pleiotropic effects of smoking. In the brain, uncontrolled stimulation of nAChRs is thought to mediate the addictive effects of tobacco (Changeux, 2010). In other tissues, smoking can produce toxic as well as carcinogenic effects. These latter depend on long-term exposure to several tobacco metabolites, especially the N-nitrosamines (here simply referred to as "nitrosamines"; Hecht and Hoffmann, 1988). When metabolically activated, these drugs cause DNA mutations, particularly $\mathrm{G}$ to $\mathrm{T}$ transversions that may lead to mutation of k-ras and p53 (Pfeifer et al., 2002). Nonetheless, many harmful effects of the tobaccorelated nitrosamines may be attributed to direct targeting of nAChRs. In fact, the nitrosamines that produce the most potent biological effects are structural analogs of either ACh (e.g., diethylnitrosamine) or nicotine (especially NNK and NNN; Figure 1). All of these compounds can bind to nAChRs (Schuller and Orloff, 1998; Schuller, 2007). Although nicotine is not carcinogenic, engagement of $\mathrm{nAChRs}$ with either nicotine or nitrosamines can promote the neoplastic progression in cultured cells, by stimulating cell cycle, migration, angiogenesis, epithelialto-mesenchymal transition, and inhibiting apoptosis (Schuller, 1989; Maneckjee and Minna, 1990; Heeschen et al., 2001; Arredondo et al., 2006; Guo et al., 2008; Paleari et al., 2008; Song et al., 2008; Al-Wadei and Schuller, 2009; Calleja-Macias et al., 2009; Dasgupta et al., 2009). Similar evidence is slowly accumulating in vivo (Heeschen et al., 2001; Paleari et al., 2009).

The pathophysiological interpretation of these studies requires to clarify the signaling pathways downstream to $\mathrm{nAChR}$ binding (West et al., 2003; Tsurutani et al., 2005; Guo et al., 2008; Ambrosi and Becchetti, 2013). However, a general hindrance to full comprehension of the cellular effects of nitrosamines is that the direct functional action of these drugs on nAChRs is largely unknown. The only such study currently available shows that NNN inhibits $\alpha 3 \beta 4 \mathrm{nAChR}$ at high concentrations ( $\mathrm{IC}_{50}$ was $1.14 \mathrm{mM}$, in the presence of $100 \mu \mathrm{M}$ nicotine), whereas it exerts little effect on the muscle subtype (Nunes-Alves et al., 2012). The lack of direct functional tests is a major lacuna, as binding studies alone cannot distinguish whether a certain compound directly activates or inhibits nAChRs, nor the related kinetics. Moreover, the downstream cell signals could be regulated by conductive as well as non-conductive mechanisms (Becchetti, 2011). Understanding the functional interplay between nitrosamines and ACh or nicotine is also necessary to interpret their effects in the brain. Smokers are exposed to a mixture of tobacco-related nAChR ligands. Compounds

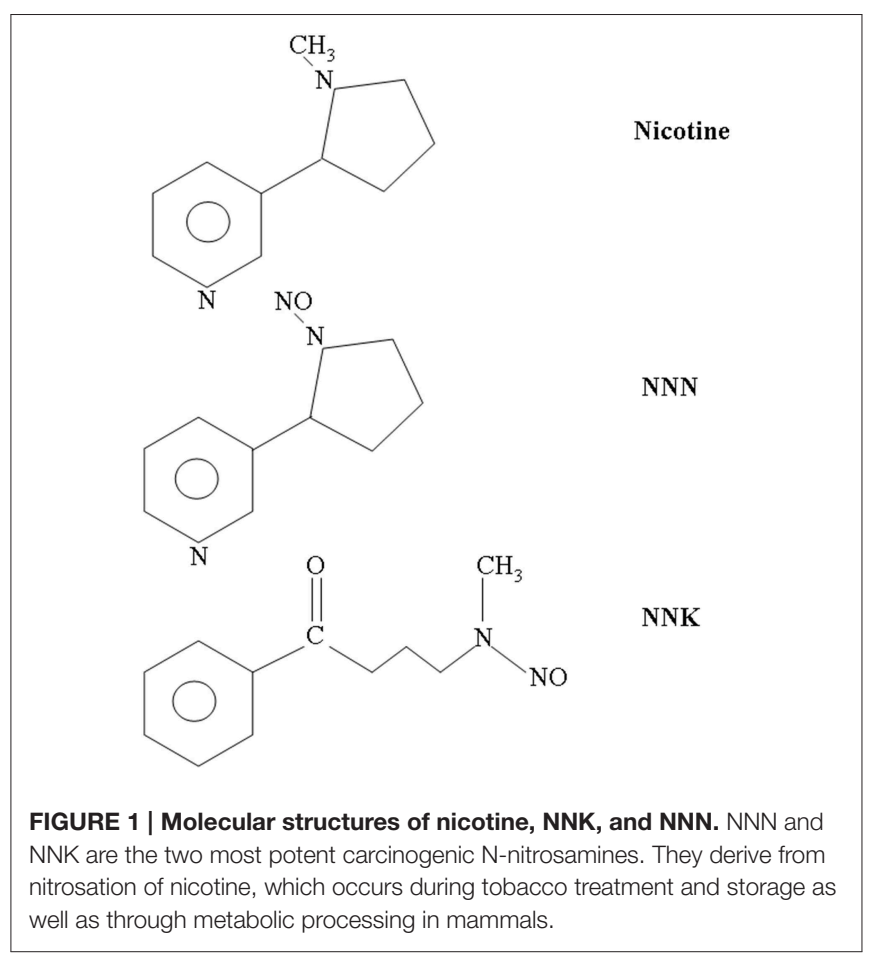

such as NNK easily traverse the blood brain barrier (Jorquera et al., 1992; Gerde et al., 1998; Berridge et al., 2010) and have been found to activate microglia in vivo (Ghosh et al., 2009). These molecules are likely to interfere with one another and with the physiological agonist, to alter synaptic transmission and regulate tobacco addiction in currently unpredictable ways.

We studied by patch-clamp methods the effect of NNK and NNN on human $\alpha 4 \beta 2$ nAChRs stably expressed in HEK cells. This nAChR subtype is widely distributed in the brain, where it regulates both excitatory and inhibitory transmission (Becchetti et al., 2015) and is implicated in the cognitive and addictive effects of smoking (Changeux, 2010; Faure et al., 2014). It is also commonly expressed in non-nervous tissue, including lung cells (Fu et al., 2009), and tumor cell lines (Egleton et al., 2008). We found that these nitrosamines exert distinct actions, as NNK is a partial agonist, whereas NNN is a pure inhibitor of $\alpha 4 \beta 2$ nAChRs.

\section{Materials and Methods}

\section{Cell Cultures}

HEK 293 cells stably expressing human $\alpha 4 \beta 2$ nAChRs were cultured by standard methods (Di Resta et al., 2010). In brief, cultures were maintained in Dulbecco's modified Eagle's medium (Hyclone Laboratories), supplemented with $10 \%$ fetal calf serum (Hyclone), $4.5 \mathrm{~g} / \mathrm{l}$ glutamine, $0.05 \mathrm{ng} / \mathrm{ml}$ hygromycin $\beta$, and $0.25 \mu \mathrm{g} / \mathrm{ml}$ amphoterycin $\mathrm{B}$. Cells were grown at $37^{\circ} \mathrm{C}$ and $5 \% \mathrm{CO}_{2}$. For patch-clamp experiments, cells were harvested by treatment with trypsin and plated onto $35 \mathrm{~mm}$ Petri dishes (Corning Inc.). 


\section{Patch-clamp Recording}

Cells were voltage-clamped by using the whole-cell configuration of the patch-clamp method. Currents were registered with an Axopatch 200B amplifier (Molecular Devices), at room temperature $\left(20-22^{\circ} \mathrm{C}\right)$. Micropipettes (3-4 M $\Omega$ ) were pulled from borosilicate capillaries (GMBH) with a P-97 Flaming/Brown Micropipette Puller (Sutter Instrument Co.). The cell capacitance and series resistance (up to about $75 \%$ ) were always compensated. Currents were low-pass filtered at $2 \mathrm{kHz}$ and acquired on-line at $5-10 \mathrm{kHz}$ with Molecular Devices hardware and software (pClamp 8 and Axoscope 8). After patch rupture, we usually allowed 1-2 min for pipette solution exchange and signal stabilization, before applying our stimuli. Extracellular solutions were applied with an RSC-160 Rapid Solution Changer (BioLogic Science Instruments). The solution is delivered to the cells through borosilicate capillaries connected to Tygon tubes. Seven independent lines are available. Each line was generally reserved to one compound at a given concentration. The perfusing line was totally substituted whenever the drug was changed. No corrections for leak or junction potentials was ever applied to any of the displayed results.

\section{Solutions and Drugs}

Unless otherwise indicated, chemicals, and drugs were purchased by Sigma-Aldrich Italia Srl. The extracellular solution contained (mM): $\mathrm{NaCl} 130, \mathrm{KCl} 5, \mathrm{CaCl}_{2} 2, \mathrm{MgCl}_{2}$ 2, HEPES 10, Dglucose 5 ( $\mathrm{pH} 7.4$; adjusted with $\mathrm{NaOH}$ ). Pipettes contained (mM): K-aspartate $120, \mathrm{NaCl} 10, \mathrm{MgCl}_{2} 2, \mathrm{CaCl}_{2} 1.3$, EGTA-KOH 10, HEPES 10, MgATP 1, (pH 7.3; adjusted with KOH). Stock solutions of nicotine (up to $10 \mathrm{mM}$ ) were prepared weekly in our external solution and kept refrigerated. The $\mathrm{pH}$ was always checked after nicotine addition. NNK and NNN (20 mM) were dissolved in water and kept refrigerated for no longer than 1 week. Nicotine and/or nitrosamines were added daily to the extracellular solution. The final concentrations were obtained by serial dilution.

\section{Analysis of Data}

Data were analyzed with Clampfit 9.2 (Molecular Devices) and OriginPro 9 (OriginLab Co.). Theoretical curves best fitting the data were determined by a nonlinear least-squares method (Levenberg-Marquardt algorithm). For nAChR activation we used both a simple Hill function and the sum of two Hill expressions (Covernton and Connolly, 2000). The single-term expression was:

$$
\frac{I_{L}}{I_{\max }}=\frac{1}{\left(1+\frac{E C_{50}}{[L]}\right)^{n_{H}}}
$$

where $I_{\max }$ is the maximal current, $I_{\mathrm{L}}$ is the peak current at a given concentration of agonist $L, \mathrm{EC}_{50}$ is the concentration of $L$ at which $I_{L} / I_{\max }=0.5$, and $n_{\mathrm{H}}$ is the Hill coefficient.

The two-terms Hill expression was:

$$
\frac{I_{L}}{I_{\max }}=\frac{A}{\left(1+\frac{E C_{50 h i g h}}{[L]}\right)^{n_{H 1}}}+\frac{1-A}{\left(1+\frac{E C_{50 l o w}}{[L]}\right)^{n_{H 2}}}
$$

where $A$ is the fraction of receptors in the high-affinity state; $\mathrm{EC}_{50 \text { high }}$ and $\mathrm{EC}_{50 \text { low }}$ are the $\mathrm{EC}_{50}$ values of the components at high and low affinity, respectively; $n_{\mathrm{H} 1}$ and $n_{\mathrm{H} 2}$ are the corresponding Hill coefficients, and the other symbols are as in Equation (1).

The function used to fit the desensitization data points (Figure 3) was:

$$
\frac{I_{S S}}{I_{\text {peak }}}=B+\frac{1-B}{\left(1+\frac{[L]}{I C_{50}}\right)^{n_{H}}}
$$

where $I_{S S}$ is the average steady state current at a given concentration of agonist $L, I_{\text {peak }}$ is the corresponding peak current, $B$ is the minimal fractional steady state current, $\mathrm{IC}_{50}$ is the concentration of $L$ at which $I_{S S} / I_{\text {peak }}=0.5$, and $n_{\mathrm{H}}$ is the Hill coefficient. $I_{S S}$ was found by fitting the current decay with a single exponential function and taking the steady state value of this function. A similar function was used to fit the fractional inhibition in Figures 4B, 5B.

The function used to fit the concentration-response data for nicotine at a given $\mathrm{NNk}$ concentration (Figure $5 \mathrm{C}$; red continuous line) was:

$$
y=\frac{\alpha_{N i c} \frac{[N i c]}{E C_{50}}+\frac{\alpha_{N N K}[N N K]}{E C_{50(N N K)}}}{1+\frac{[N i c]}{E C_{50}}+\frac{[N N K]}{E C_{50(N N K)}}}
$$

where $y$ is the fractional current in the presence of NNK plus nicotine, $\alpha_{\mathrm{Nic}}$ and $\alpha_{\mathrm{NNK}}$ are the maximal fractional responses produced by nicotine and NNK, respectively (also named intrinsic activities of the agonists; Hogg and Bertrand, 2007); [Nic] and $[\mathrm{NNK}]$ are, respectively, the concentrations of nicotine and $\mathrm{NNK} ; \mathrm{EC}_{50}$ and $\mathrm{EC}_{50(\mathrm{NNK})}$ are, respectively, the $\mathrm{EC}_{50}$ values for nicotine and NNK. The model is simplified in that it only considers single $\mathrm{EC}_{50}$ 's for both the full and the partial agonist.

\section{Statistics}

Data are given as mean values \pm standard error of the mean, with $n$ indicating the number of determinations (i.e., the number of cells tested). Statistical significance was determined with twotailed $t$-test for paired or unpaired samples, as appropriate, at the indicated significance level $(p)$. Normality was tested by the Kolmogorov-Smirnov test.

\section{Results}

\section{NNK Activates Human $\alpha \mathbf{4} \beta \mathbf{2}$ nAChRs}

We first tested if NNK can activate $\alpha 4 \beta 2$ nAChRs, by applying the drug at $-80 \mathrm{mV}$. A representative example is shown in Figure 2A. Consecutive applications of different NNK concentrations were spaced 2-3 min apart, to permit full recovery from $\mathrm{nAChR}$ desensitization. NNK concentrations higher than $10 \mathrm{nM}$ elicited inward currents, and the maximal effect was obtained at $100 \mu \mathrm{M}$ NNK. Nicotine was usually applied at the beginning and at the end of the experiment, to check for possible current rundown. The concentration-response relation for NNK 
was obtained by plotting the average fractional peak currents obtained at the indicated NNK concentrations (Figure 2B). On average, the current elicited by $100 \mu \mathrm{M}$ NNK was approximately $14 \%$ of the current activated by saturating concentrations of nicotine $(300 \mu \mathrm{M})$. No significantly higher currents were observed when using $300 \mu \mathrm{M}$ NNK. For both nicotine and NNK, data points were fitted with Equation 1, which gave apparent EC $_{50}$ 's of approximately $28 \mu \mathrm{M}$ for nicotine and $17 \mu \mathrm{M}$ for NNK. For all kinetic parameters, detailed statistics are given in the figure legends, which also report the Hill coefficients. For easier consulting, the main results are summarized in Table 1.

The current activated by NNK was strongly blocked by $1 \mu \mathrm{M}$ dihydro- $\beta$-erythroidine ( $\mathrm{DH} \beta \mathrm{E})$, which is known to inhibit $\alpha 4 \beta 2$, but not homomeric, nAChRs (Buisson et al., 1996; Alkondon et al., 2000). To allow equilibration of $\mathrm{DH} \beta \mathrm{E}$ concentration, this compound was perfused in the bath for $30 \mathrm{~s}$ before the agonist was added. To generate the data shown in Figure 2C, the peak current measured in the presence of agonist plus inhibitor was divided by the one elicited by the agonist alone. These fractional residual currents were plotted for NNK $(10 \mu \mathrm{M})$, nicotine $(300 \mu \mathrm{M})$, and $\mathrm{ACh}(300 \mu \mathrm{M})$. DH $\beta \mathrm{E}$ blocked more than $90 \%$ of the currents activated by either agonist, which is consistent with our hypothesis that NNK specifically activated the $\alpha 4 \beta 2$ nAChRs expressed in our cells.

A more detailed analysis of the concentration-response relations for nicotine and NNK is shown in Figure 3. Best fitting of the experimental data points was obtained by using the two-terms Hill function (Equation 2). This is usually observed with $\alpha 4 \beta 2$ nAChRs (Covernton and Connolly, 2000; Buisson and Bertrand, 2001), and is attributed to the coexistence of two receptor's stoichiometries: $(\alpha 4)_{3}(\beta 2)_{2}$ (with lower affinity) and $(\alpha 4)_{2}(\beta 2)_{3}$ receptors (with higher affinity; Nelson et al., 2003). The fitting parameters were: $\mathrm{EC}_{50 \text { high }}=0.035 \mu \mathrm{M}$ and $\mathrm{EC}_{50 \mathrm{low}}=12.81 \mu \mathrm{M}$, for $\mathrm{NNK}$, and $\mathrm{EC}_{50 \mathrm{high}}=0.14 \mu \mathrm{M}$ and $\mathrm{EC}_{50 \mathrm{low}}=7.7 \mu \mathrm{M}$ for nicotine. These results suggest that NNK is particularly effective at stimulating the high affinity nAChR component. Moreover, for both nicotine (e.g., Figure 5A) and NNK (e.g., Figure 2A), the activated current displayed progressive desensitization in the presence of the agonist. To quantify such process, the current decay was fitted with a monoexponential function (e.g., Paradiso and Steinbach, 2003). Next, desensitization curves were generated by plotting the average fractional steady state currents calculated from the fitting procedure, for the indicated agonist concentration (Figure 3). By using Equation 3 (continuous lines through the data points), we estimated $\mathrm{IC}_{50}=1.7 \mu \mathrm{M}$ for $\mathrm{NNK}$, and $\mathrm{IC}_{50}=2.64 \mu \mathrm{M}$ for nicotine. In the absence of other nicotinic ligands, the $\mathrm{AAChR}$-dependent biological effect of NNK must depend on the steady state current sustained by this drug. This is proportional to the product of the activation and desensitization curves (sometimes referred to as "window current"), at a given NNK concentration. Figure 3 suggests that the window currents of NNK and nicotine are broadly similar, but that NNK tends to be comparatively more effective at the low concentrations, in line with the range of plasma doses observed in smokers.

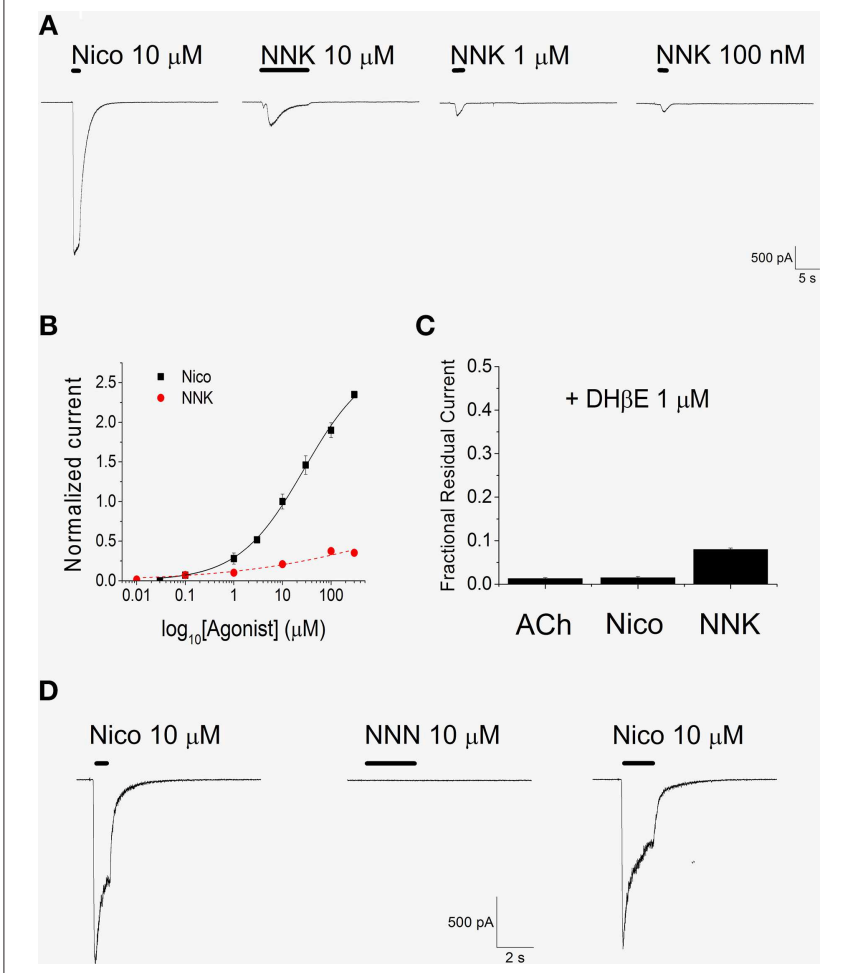

FIGURE 2 | NNK, but not NNN, activates $\alpha \mathbf{4} \mathbf{\beta 2}$ nAChRs. (A) Consecutive whole-cell current traces, elicited at $-80 \mathrm{mV}$ by the indicated compound. Tests were spaced 2-3 min apart (gaps in the continuous current trace). Continuous bars above the current traces indicate the time of agonist application. Nicotine was repeatedly applied during the experiment to check for possible current rundown. (B) Concentration-response relations for nicotine (black squares) and NNK (red circles). Data points are average peak whole-cell currents recorded at $-80 \mathrm{mV}$, normalized to the current elicited by $10 \mu \mathrm{M}$ nicotine and plotted against the agonist concentration (in $\log _{10}$ scale). Each point is the average of at least seven determinations. The concentration-response relation for nicotine (continuous line) and that for NNK (dashed line) were fitted with Equation 1, which gave an $\mathrm{EC}_{50}=27.8 \pm 5.6 \mu \mathrm{M}\left(n_{H}=0.64\right)$ for nicotine and $16.7 \pm 20 \mu \mathrm{M}\left(n_{H}=0.44\right)$ for NNK. The estimated maximal current activated by NNK was approximately $16 \%$ of the current elicited by $300 \mu \mathrm{M}$ nicotine. The measured peak current in the presence of $100 \mu \mathrm{M}$ NNK was $0.14 \pm 0.02$ $(n=13)$ of the value measured in the presence of $300 \mu \mathrm{M}$ nicotine. (C) $\mathrm{DH} \beta \mathrm{E}$ $(1 \mu \mathrm{M})$ strongly blocked the currents elicited by $300 \mu \mathrm{M}$ ACh, $300 \mu \mathrm{M}$ nicotine and $10 \mu \mathrm{M} N$ NK, as indicated. Data are averages of at least seven determination for each condition, carried out at $-80 \mathrm{mV}$. Bars display the fractional residual currents (i.e., the peak current measured in the presence of the agonist plus $\mathrm{DH} \beta \mathrm{E}$ divided by the peak current activated by the agonist alone). In the presence of $10 \mu \mathrm{M} N N K, D H \beta E$ brought the average peak current density (pA/pF) from $5.75 \pm 1.22$ to $0.53 \pm 0.199(p<0.01$ with paired $t$-test; $n=9)$. (D) Comparison of the effects of NNN $(10 \mu \mathrm{M})$ and nicotine $(10 \mu \mathrm{M})$ on whole-cell currents from $\alpha 4 \beta 2 \mathrm{nAChRs}$, at $-80 \mathrm{mV}$. NNN never produced $n A C h R$ activation in cells in which functional receptors were shown to be present by nicotine application.

\section{The Inhibitory Effect of NNN}

Differently from NNK, NNN did not elicit any whole-cell current even at concentrations $(100 \mu \mathrm{M})$ much higher than those encountered in physiological conditions. Figure 2D shows a typical experiment at $-80 \mathrm{mV}$, comparing the effects of $10 \mu \mathrm{M}$ nicotine and $10 \mu \mathrm{M} N N$, in a cell expressing a large nicotinic current. Once again, nicotine was applied before and after NNN, 
TABLE 1 | Comparison of the effects of nicotine, NNN, and NNK, on $\alpha 4 \beta 2$ nAChRs.

\begin{tabular}{|c|c|c|c|c|c|c|}
\hline \multirow[t]{2}{*}{ Compound } & \multirow[t]{2}{*}{$I_{\max } / I_{\text {nico }}$} & \multirow[t]{2}{*}{$\mathrm{EC}_{50}(\mu \mathrm{M})$} & $\mathrm{EC}_{50 h i g h}$ & \multirow[t]{2}{*}{$E C_{50 / o w}$} & \multirow[t]{2}{*}{ Desensitization $\mathrm{IC}_{50}(\mu \mathrm{M})$} & \multirow[t]{2}{*}{ Inhibition $\mathrm{IC}_{50}(\mu \mathrm{M})$} \\
\hline & & & $(\mu \mathrm{M})$ & & & \\
\hline Nicotine & 1 & $27.8\left(n_{H}=0.65\right)$ & $0.14\left(n_{H 1}=1.1\right)$ & $7.7\left(n_{H 2}=2.1\right)$ & $2.64\left(n_{H}=1.8\right)$ & N.A. \\
\hline NNK & 0.16 & $16.7\left(n_{H}=0.44\right)$ & $0.035\left(n_{H 1}=1.2\right)$ & $12.81\left(n_{H 2}=1.4\right)$ & $1.7\left(n_{H}=0.9\right)$ & >100 (with $10 \mu \mathrm{M}$ nicotine) \\
\hline NNN & 0 & N.A. & \multicolumn{2}{|c|}{ N.A. } & N.A. & 0.00021 (with $10 \mu \mathrm{M}$ nicotine) \\
\hline
\end{tabular}

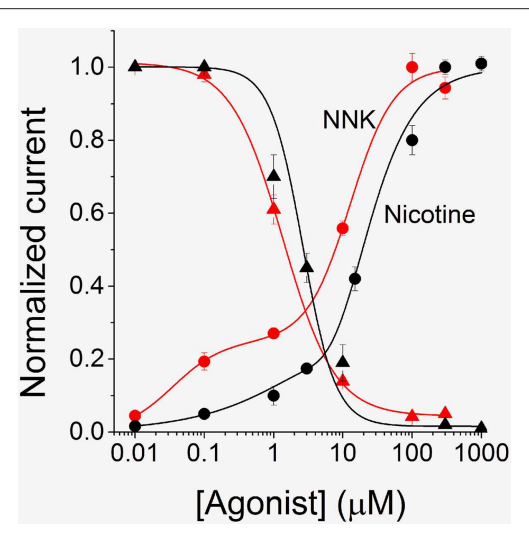

FIGURE 3 | Activation and desensitization profiles for $\alpha 4 \beta 2$ nAChRs. The activation curve for NNK (red circles) was generated by using experiments analogous to those shown in Figure 2. The average peak current measured at each concentration of NNK was normalized to the current elicited by $300 \mu \mathrm{M}$ NNK. Data points are averages of at least seven determinations and were fitted by using Equation 2 (continuous line), which gave $\mathrm{EC}_{50 h i g h}=0.035 \pm$ $0.012 \mu \mathrm{M}\left(n_{\mathrm{H} 2}=1.2\right)$, and $\mathrm{EC}_{5 \text { olow }}=12.81 \pm 1.58 \mu \mathrm{M}\left(n_{\mathrm{H} 1}=1.4\right)$. The desensitization curve for NNK was generated by plotting average steady state fractional currents (red triangles), as a function of NNK concentration. At each concentration, the current decay in the presence of the drug was fitted with a single exponential function. The steady state current values thus estimated were divided by the corresponding peak current values. Data points are averages of at least 6 determinations and were fitted by using Equation 3 (continuous line), which gave $\mathrm{IC}_{50}=1.7 \mu \mathrm{M} \pm 0.2\left(n_{H}=0.9\right)$. The nicotine activation (black circles) and desensitization (black triangles) curves were obtained in a similar way. For activation, data points are averages of at least 6 determinations. They were fitted by using Equation 2 (continuous line), giving $\mathrm{EC}_{50 \text { high }}=0.14 \pm 1.03 \mu \mathrm{M}\left(n_{\mathrm{H} 2}=0.62\right)$, and $\mathrm{EC}_{50 \text { low }}=7.7 \pm 14.7 \mu \mathrm{M}$ $\left(n_{\mathrm{H} 1}=1.8\right)$. For desensitization, data points were fitted with Equation 3 (continuous line), which gave $\mathrm{IC}_{50}=2.64 \pm 0.47 \mu \mathrm{M}\left(n_{\mathrm{H}}=1.84\right)$.

to exclude channel rundown. Given that NNN produced no nAChR activation, we studied its possible inhibitory effect in the presence of nicotine. We tested NNN concentrations between $1 \mathrm{pM}$ and $100 \mu \mathrm{M}$ on currents activated by concentrations of nicotine ranging between $10 \mathrm{nM}$ and $100 \mu \mathrm{M}$. A representative current trace is shown in Figure 4A, in which $10 \mu \mathrm{M} \mathrm{NNN}$ was applied in the presence of $10 \mu \mathrm{M}$ nicotine, at $-80 \mathrm{mV}$. NNN was generally applied until the effect had reached the steady state. Next, the drug was removed. After the current had recovered from inhibition, nicotine was also washed out. This experimental procedure (Buisson et al., 1996; Palma et al., 1996) was preferred to the alternative procedure of pre-conditioning with NNN and then applying simultaneously the agonist and the antagonist (as we did with $\mathrm{DH} \beta \mathrm{E}$ ). The former method allows to directly compare the effect of NNN with the one produced by nicotine. In this way, the possible artifacts occurring in repetitive consecutive trials (such as channel rundown, poor solution exchange, precise estimation of the current peak, etc.) are avoided or immediately recognized. Moreover, the blockade kinetics can be directly appreciated. For each concentration, the steady state current in the presence of NNN was divided by the current remaining after NNN was removed. These fractional currents were plotted in Figure 4B, as a function of the NNN concentration, for the indicated nicotine concentrations $(0.5$, 10 , and $100 \mu \mathrm{M})$. Notice that higher nicotine concentrations decreased the inhibitory effect of NNN, which suggests a competitive blocking mechanism. For instance, the $\mathrm{IC}_{50}$ value for NNN was $>10 \mu \mathrm{M}$ in the presence of $100 \mu \mathrm{M}$ nicotine, whereas it was approximately $1 \mathrm{nM}$ in the presence of $10 \mu \mathrm{M}$ nicotine (full statistics are reported in the figure legend). Conversely, the concentration-response relations for nicotine in the presence of the indicated NNN concentrations are plotted in Figure 4C. Data points were fitted with Equation 1 (continuous lines through the data points). The right-shift of the curves produced by NNN is consistent with the notion that this drug tends to produce competitive block of $\alpha 4 \beta 2$ nAChRs. From a pathological point of view, it is worth noticing that NNN can exert significant current block at concentrations normally encountered in smokers' plasma (<100 pM; Schuller, 2007).

\section{The Effect of NNK in the Presence of Nicotine}

NNK is expected to produce effects more complex than those shown by $\mathrm{NNN}$, as partial agonists can produce channel activation or inhibition depending on the concentration of the full agonist (e.g., Hogg and Bertrand, 2007; Rollema et al., 2007). In fact, concentrations of NNK up to $100 \mathrm{nM}$ produced no effect on the currents activated by $10 \mu \mathrm{M}$ nicotine, whereas higher concentrations progressively inhibited $\alpha 4 \beta 2$ nAChRs (Figure 5A). These data were obtained and analyzed as previously illustrated for NNN. Figure 5B plots the average fractional residual currents measured in the presence of $10 \mu \mathrm{M}$ nicotine, as a function of NNK concentration. Data points were fitted with Equation 3 (continuous line), giving an $\mathrm{IC}_{50}>100 \mu \mathrm{M}$. In contrast, the currents activated by low concentrations of nicotine could be potentiated by NNK. An example is given in the bottom panel of Figure 5A, showing that $100 \mu \mathrm{M}$ NNK increased the current activated by $100 \mathrm{nM}$ nicotine at $-80 \mathrm{mV}$, by approximately $80 \%$. In agreement with the results shown in Figure 3, the current activated by $100 \mu \mathrm{M}$ NNK also displayed progressive desensitization. The effects of the tested concentrations of NNK on the currents activated by different 

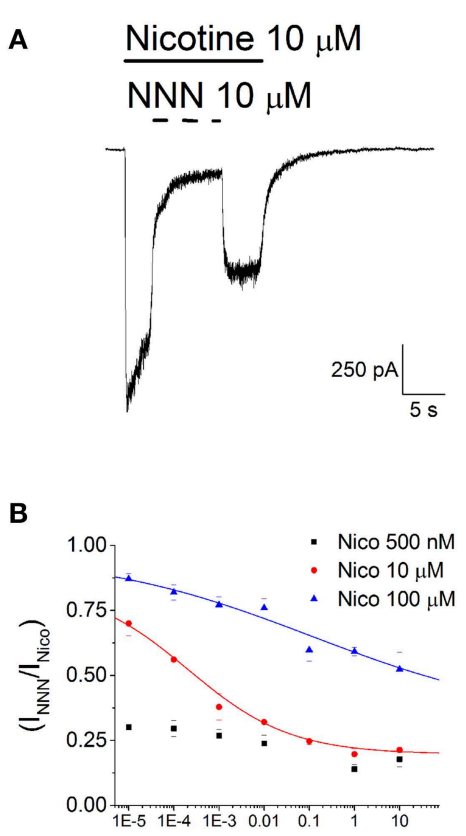

[NNN] $(\mu \mathrm{M})$

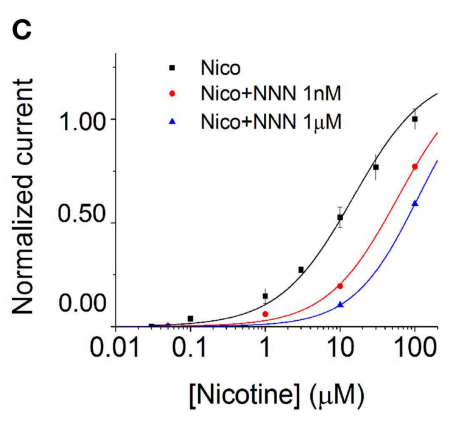

FIGURE 4 | NNN inhibits $\alpha \mathbf{4 \beta 2}$ nAChRs. (A) Typical whole-cell current traces elicited by $10 \mu \mathrm{M}$ nicotine at $-80 \mathrm{mV}$, in the presence and in the absence of $10 \mu \mathrm{M}$ NNN. Horizontal bars mark time of application of the indicated compound. (B) Steady state inhibition curves were generated by plotting the residual fractional steady state currents as a function of NNN concentration (in $\log _{10}$ scale). The different data sets were obtained at the indicated concentration of nicotine. Data points are averages of at least nine determinations. Lines through the data points are best fitting curves, obtained with Equation 3. At $100 \mu \mathrm{M}$ nicotine, $\mathrm{IC}_{50}$ was $>20 \mu \mathrm{M}$, whereas at $10 \mu \mathrm{M}$ nicotine $\mathrm{IC}_{50}$ was $0.21 \pm 0.4 \mathrm{nM}$. (C) Activation curves in the absence (black squares) or in the presence of the indicated concentration of NNN. Data points are peak whole-cell currents normalized to the current elicited by, $100 \mu \mathrm{M}$ nicotine. Continuous lines through the data points are best fitting curves, obtained with Equation 1. The corresponding parameters were: $\mathrm{EC}_{50}=14.5$ $\pm 1.34 \mu \mathrm{M}\left(n_{\mathrm{H}}=0.83\right)$, for nicotine alone; $\mathrm{EC}_{50}=58.3 \pm 4.4 \mu \mathrm{M}\left(n_{\mathrm{H}}=0.92\right)$, in the presence of $1 \mathrm{nM} \mathrm{NNN}$; $\mathrm{EC}_{50}=109.1 \pm 0.14 \mu \mathrm{M}\left(n_{\mathrm{H}}=1\right)$, in the presence of $1 \mu \mathrm{M}$ NNN.

concentrations of nicotine are summarized in Figure 5C. For comparison, the activation curve for nicotine (black circles) is also reported. With $1 \mu \mathrm{M}$ NNK (red squares), the potentiation produced on the currents activated by $0.01 \mu \mathrm{M}$ nicotine was $26 \%$. The concentration of nicotine at which the drug reversed its effect was around $20 \mathrm{nM}$, as is estimated by fitting the data points with the simplified model expressed by Equation 4 (continuous red line). Saturating concentrations of NNK (100 $\mu \mathrm{M}$; red circles) potentiated by about $80 \%$ the current activated by $0.1 \mu \mathrm{M}$ nicotine, whereas they inhibited by $40 \%$ the current elicited by $10 \mu \mathrm{M}$ nicotine. In this case, the sign reversal of NNK effect can be estimated to occur at approximately $400 \mathrm{nM}$ nicotine. For clarity, the error bars are not reported in Figure 5C. Instead, the statistics of the current potentiation observed with NNK are reported in detail in Figure 5D and in the figure legend. We conclude that NNK, consistently with its partial agonist nature, can produce either potentiation or inhibition of $\alpha 4 \beta 2 \mathrm{nAChRs}$, depending on the concomitant concentration of the full agonist.

\section{The Block Produced by NNN and NNK was not Voltage-dependent}

The voltage dependence of the NNN and NNK effect is illustrated in Figure 6. Current traces (Figure 6A) illustrate typical experiments in which nAChRs were activated by $10 \mu \mathrm{M}$ nicotine, at the indicated $\mathrm{V}_{\mathrm{m}}$. For briefness, only traces obtained at $-80 \mathrm{mV}$ (left) and $+80 \mathrm{mV}$ (right) are shown. NNN $(10 \mu \mathrm{M})$ was applied in the presence of nicotine and removed after inhibition had reached the steady state. These results are summarized in Figure 6B (top panel), showing the current voltage relations in the presence of either nicotine alone (Nico) or nicotine plus NNN (NNN). Data points are average current values normalized to the absolute value of the current measured at $-80 \mathrm{mV}$. The I/V plots displayed the typical inward rectification of $\alpha 4 \beta 2$ nAChRs. Analogous results were obtained with NNK (Figure 6C, top panel). The apparent reversal potential $\left(\mathrm{V}_{\text {rev }}\right)$ was usually between +5 and $+20 \mathrm{mV}$. The fractional block produced by either NNN or NNK at the steady state was independent of the applied $\mathrm{V}_{\mathrm{m}}$. This is better appreciated in the bottom panels of Figures $6 \mathrm{~B}, \mathrm{C}$, which give the average fractional residual currents as a function of $\mathrm{V}_{\mathrm{m}}$, in the presence of $\mathrm{NNN}$ or $\mathrm{NNK}$, respectively. The data points around $V_{\text {rev }}$ were removed as the small current values prevented a reliable measure of the drugs' effect. The quick development and reversal of channel block suggests that the effect was mainly caused by the nitrosamines accessing to the channel from the extracellular milieu (i.e., we assume that intracellular accumulation of the drugs was negligible). Hence, because inhibition was virtually independent of the net direction of ion flow, these nitrosamines are unlikely to exert significant open channel block, at the concentrations we applied (much higher than those observed in vivo).

\section{Discussion}

\section{Comparison with Previous Studies}

Binding of nitrosamines to nAChRs was previously studied with radioactive ligand competition assays. These were mostly carried out in lung cancer cell lines, by using labeled epibatidine (to target heteromeric nAChRs) or $\alpha$-bungarotoxin (specific for $\alpha 7$; Schuller and Orloff, 1998; Schuller, 2007). Our results qualitatively agree with these studies in that our nitrosamines compete with the full agonist for binding to nAChRs. However, a detailed quantitative comparison is difficult to draw. First, tumor 


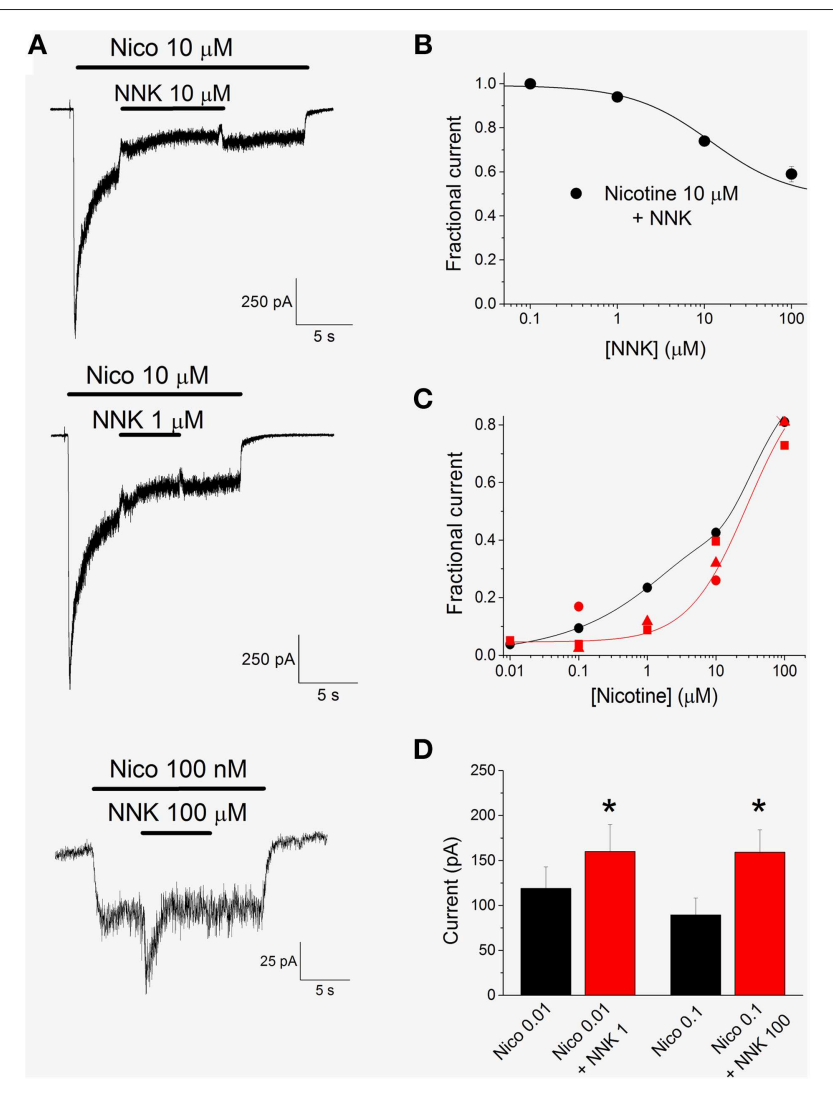

FIGURE 5 | The effect of NNK on $\alpha \mathbf{4} \beta 2$ nAChRs, in the presence of nicotine. (A) Representative current traces elicited at $-80 \mathrm{mV}$ by the indicated concentration of nicotine (Nico), in the presence or in the absence of the indicated concentration of NNK. The currents elicited by $10 \mu \mathrm{M}$ nicotine (top and middle panels) are representative of 11 similar experiments. The bottom panel illustrates the potentiating effect of $100 \mu \mathrm{M}$ NNK on the current activated by $100 \mathrm{nM}$ nicotine (representative of eight similar experiments). Bars mark the time of application of nicotine and NNK, as indicated. (B)

Concentration-response relation for the inhibitory effect of NNK tested on currents activated by $10 \mu \mathrm{M}$ nicotine, as illustrated in (A). Data points are average steady state currents $(n=11)$ measured in the presence of a given NNK concentration, divided by the current obtained after NNK was rinsed. Continuous line through the data points is best fitting to Equation 3, giving $\mathrm{IC}_{50}$ $>100 \mu \mathrm{M}\left(n_{\mathrm{H}}=0.95\right)$. (C) Summary of the effects of NNK plus nicotine. All data are normalized to the current measured with $300 \mu \mathrm{M}$ nicotine. Black circles: concentration-response for nicotine (same as in Figure 3; only concentrations up to $100 \mu \mathrm{M}$ are shown). Red symbols: average fractional currents in the presence of $1 \mu \mathrm{M}$ (squares), $10 \mu \mathrm{M}$ (triangles), or $100 \mu \mathrm{M}$ (squares) NNK, as a function of [nicotine]. Data were obtained as illustrated in (A). The values obtained with NNK were generally significantly different from those obtained with nicotine alone. Detailed statistics for the potentiation data are given in (D). The red continuous line is the curve best fitting the data points relative to $1 \mu \mathrm{M}$ NNK, obtained by using Equation 4. The fit parameters were $A=1, B=0.27$, $[\mathrm{NNK}]=1 \mu \mathrm{M}, \alpha_{\mathrm{NIC}}=24 \mu \mathrm{M}, \alpha_{\mathrm{NNK}}=5 \mu \mathrm{M}$. (D) The peak current measured in the presence of $10 \mathrm{nM}$ nicotine was $119 \pm 24 \mathrm{pA}$, which was brought to $160 \pm$ 30 pA by $1 \mu \mathrm{M} \mathrm{NNK}(0.05<p<0.01$, with $t$-test for paired samples; $n=11)$. The effect of $100 \mu \mathrm{M}$ NNK was tested in a different series of cells, in which the average current elicited by $100 \mathrm{nM}$ nicotine was $89.4 \pm 19.4 \mathrm{pA}$, which was brought to $159.1 \pm 25.1 \mathrm{pA}$ by $100 \mu \mathrm{M}$ NNK $(0.05<p<0.01$, with $t$-test for paired samples; $n=8$ ). These results are plotted as black and red bars, respectively for nicotine (Nico) and NNK. Statistical significance is indicated by * cell lines generally express multiple $\mathrm{nAChR}$ subtypes (Egleton et al., 2008), and these have different pharmacological properties (e.g., Dani and Bertrand, 2007). Second, electrophysiological and binding analyses address different molecular features that can be difficult to reconcile (e.g., Chang and Weiss, 1999). For example, patch-clamp measurements reveal the population of active channels, whereas the binding profile can be affected by silent receptors, whose level of expression may be significant (McNerney et al., 2000). Even with those qualifications, the $\mathrm{EC}_{50}$ we observed for NNK (Figure 3) with the single-term Hill model is in good agreement with the one measured in binding studies carried out on epibatidine-sensitive nAChRs (about $17 \mu \mathrm{M}$, in SCLC cells; Schuller, 2007). The highest binding efficacy of NNN on $\alpha 4 \beta 2 \mathrm{nAChRs}$ is also in broad agreement with the binding studies. The fact that NNN inhibited $\alpha 4 \beta 2 \mathrm{nAChRs} \mathrm{(Figure} \mathrm{4)}$ is consistent with the functional studies carried out on $\alpha 3 \beta 4$ receptors, although in the latter the affinity is lower and the mechanism is mainly non-competitive (Nunes-Alves et al., 2012). Based on our results and the absence of open channel block (Figure 6), we hypothesize that the main site of nitrosamine action on $\alpha 4 \beta 2 \mathrm{nAChRs}$ is close to the orthosteric binding site.

\section{Functional Implications for Peripheral and Cancer Tissue}

Work on cell lines showed that nicotine and nitrosamines produce similar effects, particularly stimulation of proliferation and inhibition of apoptosis. In SCLC cells and gastrointestinal cancer, the effects are mainly attributed to the activation of $\alpha 7$ receptors, whereas in other neoplastic cells, such as the NSCLC, both homo- and heteromeric nAChRs contribute to the observed effects (Schuller, 2009). In brief, nAChR activation tends to stimulate exocytosis of autocrine factors (Cattaneo et al., 1993; Jull et al., 2001) as well as other $\mathrm{Ca}^{2+}$-dependent pathways that regulate proliferation and apoptosis (Schuller, 2009). The relative contribution of the different $\mathrm{nAChR}$ subtypes is still debated. One general working hypothesis is that, differently from $\alpha 7$ receptors, activation of heteromeric $\mathrm{nAChRs}$ stimulates pathways that tend to suppress cancer progression (Schuller, 2009). If this hypothesis is correct, our results suggest that NNN could stimulate tumor progression by inhibiting the protective effects contributed by heteromeric nAChRs, without affecting the less sensitive $\alpha 7$. Alternatively, NNN might exert signaling roles not depending on ion conduction (e.g., Dasgupta et al., 2006), or activate other types of membrane receptors, or both. Evidence is indeed available about the activation produced by NNK on $\beta$ adrenergic receptors (Schuller et al., 1999), but not about NNN, to the best of our knowledge.

The partial agonist nature of NNK makes it more difficult to suggest a general interpretation of its cellular effects, particularly because the direct effects of NNK on $\alpha 7 \mathrm{nAChRs}$ are currently unknown. Considering that the binding studies indicate that homomeric receptors are more sensitive to NNK, a reasonable working hypothesis is that NNK induces both homo- and heteromeric nAChR activation in cultured cells, and that the 


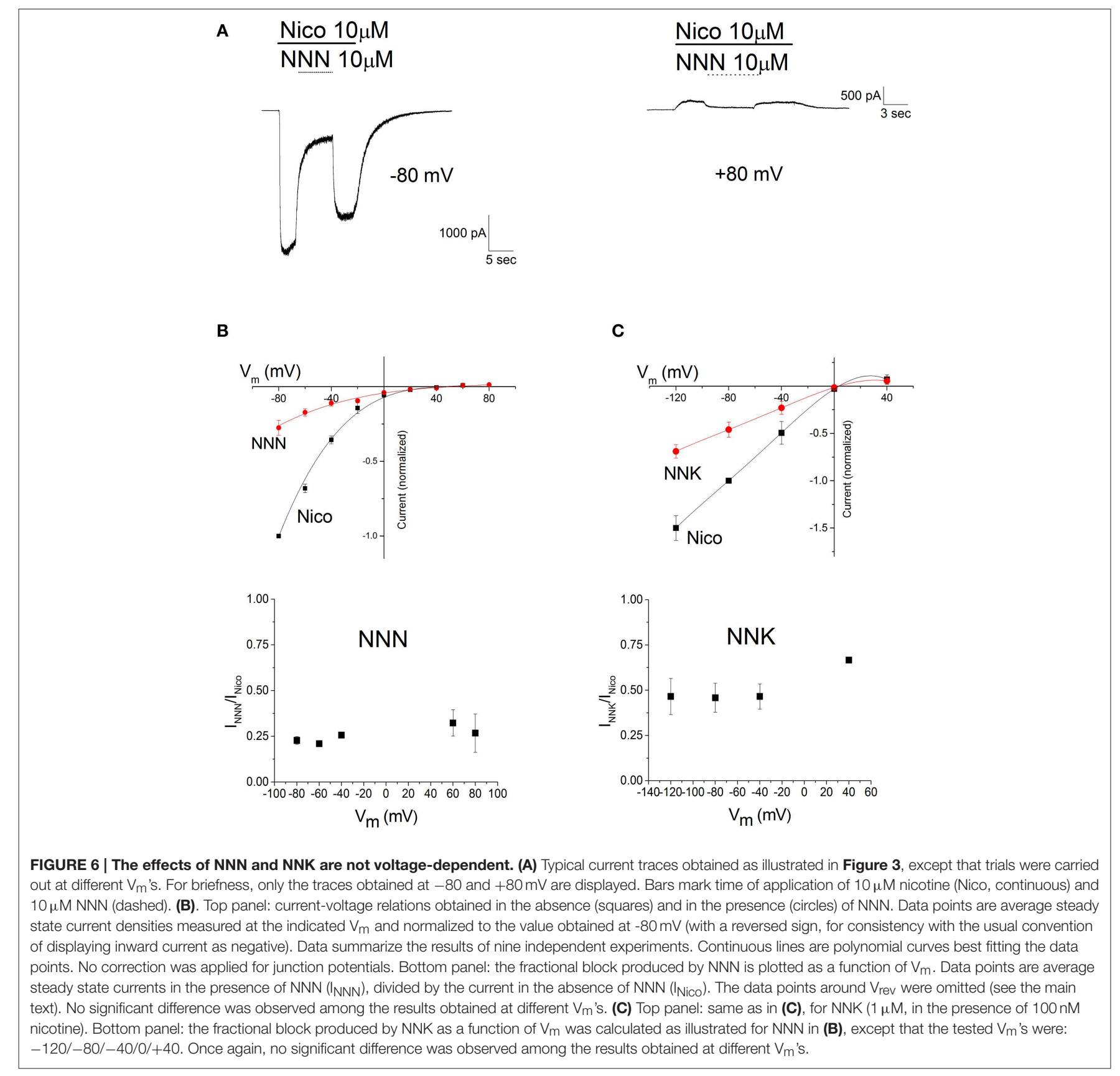

overall effect on $\mathrm{V}_{\mathrm{m}}$ and calcium signals tends to prevail on the tumor suppressing signals specifically induced by $\alpha 4 \beta 2$ activation. Moreover, although neither $\alpha 7$ (Kawai and Berg, 2001) nor $\alpha 4 \beta 2$ (Buisson and Bertrand, 2001) receptors display longterm inactivation in the presence of nicotine, the long-term effects of nitrosamines on nicotinic currents are unknown.

Even more caution is necessary to interpret the effects of the tobacco-related nitrosamines in vivo. We showed that the typical concentrations of these compounds observed in vivo can produce functional effects on $\alpha 4 \beta 2$ nAChRs. Smokers' blood contain steady nitrosamine levels around 30-50 pM, and the peak concentrations can be at least 10 times as high (e.g., Hecht and Hoffmann, 1988; Schuller, 2007). In parallel, smokers are exposed to widely fluctuating levels of plasma nicotine, depending on smoking habits, not to speak of the concomitant physiologically oscillating ACh levels depending on parasympathetic activity. How nitrosamines and the full agonists interfere in single individuals is difficult to predict, given that the typical peak concentration of plasma nicotine in smokers generally vary between 10 and $500 \mathrm{nM}$ (e.g., Russell et al., 1980), but can reach concentrations as high as $10 \mu \mathrm{M}$, immediately after smoking (Schaal and Chellappan, 2014). According to our results, this wide range of concentrations allows both potentiating and inhibiting effects of NNK, at least for $\alpha 4 \beta 2$ nAChRs. These 
observations may contribute to explain the individual variability in the response to long-term smoking. In general, our study points to the necessity of carrying out more extensive work in vitro on the combined effects of nitrosamines and the full agonists on specific nAChR subtypes.

\section{Implication for Brain Pathophysiology}

Because of their slow desensitization and high sensitivity to $\mathrm{ACh}, \alpha 4 \beta 2 \mathrm{nAChRs}$ are major regulators of the overall cerebral excitability, as is also testified by the observation that the nAChRrelated epileptogenic mutations known to date are located on genes coding for subunits of heteromeric receptors (Becchetti et al., 2015). In the mammalian neocortex, heteromeric (largely $\alpha 4 \beta 2 *$ ) nAChRs regulate excitatory (Vidal and Changeux, 1993; Gioanni et al., 1999; Lambe et al., 2003; Disney et al., 2007; Zolles et al., 2009; Poorthuis et al., 2012; Aracri et al., 2013) as well as inhibitory (Xiang et al., 1998; Porter et al., 1999; Alkondon et al., 2000; Couey et al., 2007; Aracri et al., 2010) neurotransmission at both the pre- and post-synaptic level. These receptors also regulate dopaminergic neurons, which bears implications for tobacco addiction (Faure et al., 2014).

Interpreting the effects of nitrosamines in the brain requires considering their tonic actions in resting conditions as well as the phasic effects during transmitter release. The steady concentration of nicotine in the cerebrospinal fluid of smokers is close to the plasma levels (Berridge et al., 2010). Because the tonic extracellular concentrations of ACh in the brain is thought to be in the nanomolar range (Descarries et al., 1997), the steady effects of nitrosamines in the brain likely compete mostly with nicotine, whose levels depend on the smoking regimen. Considering that $\alpha 4 \beta 2 \mathrm{nAChRs}$ display a higher affinity for $\mathrm{NNN}$, and that the latter tends to have a concentration higher than NNK, our results suggest that the inhibitory effect of NNN should prevail, in steady state conditions, irrespective of the nicotine level.

In contrast, in bona fide cholinergic synapses, on vesicle release, the ACh concentration in the synaptic cleft quickly

\section{References}

Alkondon, M., Pereira, E. F., Eisenberg, H. M., and Albuquerque, E. X. (2000). Nicotinic receptor activation in human cerebral cortical interneurons: a mechanism for inhibition and disinhibition of neuronal networks. J. Neurosci. 20, 66-75.

Al-Wadei, H. A., and Schuller, H. M. (2009). Nicotinic receptor-associated modulation of stimulatory and inhibitory neurotransmitters in NNK-induced adenocarcinoma of the lungs and pancreas. J. Pathol. 218, 437-445. doi: $10.1002 /$ path. 2542

Ambrosi, P., and Becchetti, A. (2013). Targeting neuronal nicotinic receptors in cancer: new ligands and potential side-effects. Recent Pat. Anticancer Drug Discov. 8, 38-52. doi: 10.2174/1574892811308010038

Aracri, P., Amadeo, A., Pasini, M. E., Fascio, U., and Becchetti, A. (2013). Regulation of glutamate release by heteromeric nicotinic receptors in layer $\mathrm{V}$ of the secondary motor region (Fr2) in the dorsomedial shoulder of prefrontal cortex in mouse. Synapse 67, 338-357. doi: 10.1002/syn.21655

Aracri, P., Consonni, S., Morini, R., Perrella, M., Rodighiero, S., Amadeo, A., et al. (2010). Tonic modulation of GABA release by nicotinic acetylcholine receptors in layer V of the murine prefrontal cortex. Cereb. Cortex 20, 1539-1555. doi: $10.1093 /$ cercor/bhp214 reaches millimolar levels, thus activating the postsynaptic current within hundreds of $\mu$ s. The subsequent current decay displays a kinetics that depends on tissue, largely because of the balance between intrinsic $\mathrm{nAChR}$ desensitization and $\mathrm{ACh}$ removal by acetylcholinesterase, but is generally complete within 5 to $20 \mathrm{~ms}$ (e.g., Magleby and Stevens, 1972; Chu et al., 2000). Our results (Figures 4B, 5B) suggest that the typical steady state concentrations of nitrosamines normally observed in blood are probably too low to affect classic postsynaptic currents activated by high ACh levels. However, it is possible that long exposures to nitrosamine compounds could affect the nAChR sensitivity and expression.

\section{Conclusions}

The study of the interaction between nitrosamines and nAChRs is still in its infancy. Our results show that NNK behaves as a partial agonist of $\alpha 4 \beta 2 \mathrm{nAChRs}$, whereas NNN is a receptor's inhibitor, with a relatively high affinity. In light of the above discussion, these properties may explain at least in part the effects produced by nitrosamines on neoplastic cell lines. However, to reach a full biological interpretation of the nitrosamines' roles in vivo, including those in the CNS, further studies are needed along the following lines. First, the effects of NNN and NNK should be tested on other $\mathrm{nAChR}$ subtypes, particularly $\alpha 7$. Second, whether nitrosamines induce long-term inactivation of nAChRs should be also analyzed. Finally, it will be necessary to ascertain the presence of different binding sites for these drugs on the receptor's protein.

\section{Funding}

The present work was supported by the BML (Banca del Monte di Lombardia) Foundation to AB and the University of MilanoBicocca (Fondo di Ateneo per la Ricerca to AB).
Arredondo, J., Chernyavsky, A. I., and Grando, S. A. (2006). Nicotinic receptors mediate tumorigenic action of tobacco-derived nitrosamines on immortalized oral epithelial cells. Cancer Biol. Ther. 5, 511-517. doi: 10.4161/cbt.5.5.2601

Becchetti, A. (2011). Ion channels and transporters in cancer. 1. Ion channels and cell proliferation in cancer. Am. J. Physiol. Cell Physiol. 301, C255-C265. doi: 10.1152/ajpcell.00047.2011

Becchetti, A., Aracri, P., Meneghini, S., Brusco, S., and Amadeo, A. (2015). The role of nicotinic acetylcholine receptors in autosomal dominant nocturnal frontal lobe epilepsy. Front. Physiol. 6:22. doi: 10.3389/fphys.2015.00022

Berridge, M. S., Apana, S. M., Nagano, K. K., Berridge, C. E., Leisure, G. P., and Boswell, M. V. (2010). Smoking produces rapid rise of $\left[{ }^{11} \mathrm{C}\right]$ nicotine in human brain. Psychopharmacology 209, 383-394. doi: 10.1007/s00213-010-1809-8

Buisson, B., and Bertrand, D. (2001). Chronic exposure to nicotine upregulates the human $\alpha 4 \beta 2$ nicotinic acetylcholine receptor function. J. Neurosci. 21, 1819-1829.

Buisson, B., Gopalakrishnan, M., Arneric, S. P., Sullivan, J. P., and Bertrand, D. (1996). Human $\alpha 4 \beta 2$ neuronal nicotinic acetylcholine receptor in HEK293 cells: a patch-clamp study. J. Neurosci. 16, 7880-7891.

Calleja-Macias, I. E., Kalantari, M., and Bernard, H. U. (2009). Cholinergic signaling through nicotinic acetylcholine receptors stimulates the proliferation of cervical cancer cells: an explanation for the molecular role of tobacco 
smoking in cervical carcinogenesis? Int. J. Cancer 124, 1090-1096. doi: $10.1002 /$ ijc. 24053

Cattaneo, M. G., Codignola, A., Vicentini, L. M., Clementi, F., and Sher, E. (1993). Nicotine stimulates a serotonergic autocrine loop in human small-cell lung carcinoma. Cancer Res. 53, 5566-5568.

Chang, Y., and Weiss, D. S. (1999). Channel opening locks agonist onto the GABA $_{C}$ receptor. Nat. Neurosci. 2, 219-225. doi: 10.1038/6313

Changeux, J. P. (2010). Nicotine addiction and nicotinic receptors: lessons from genetically modified mice. Nat. Rev. Neurosci. 11, 389-401. doi: 10.1038/nrn2849

Chu, Z. G., Zhou, F. M., and Hablitz, J. J. (2000). Nicotinic acetylcholine receptormediated synaptic potentials in rat neocortex. Brain Res. 887, 399-405. doi: 10.1016/S0006-8993(00)03076-6

Couey, J. J., Meredith, R. M., Spijker, S., Poorthuis, R. B., Smit, A. B., Brussaard, A. B., et al. (2007). Distributed network actions by nicotine increase the threshold for spike-timing-dependent plasticity in prefrontal cortex. Neuron 54, 73-87. doi: 10.1016/j.neuron.2007.03.006

Covernton, P. J., and Connolly, J. G. (2000). Multiple components in the agonist concentration-response relationship of neuronal nicotinic acetylcholine receptors. J. Neurosci. Methods 96, 63-70. doi: 10.1016/S0165-0270(99)00185-5

Dani, J. A., and Bertrand, D. (2007). Nicotinic acetylcholine receptors and nicotinic cholinergic mechanisms of the central nervous system. Annu. Rev. Pharmacol. Toxicol. 47, 699-729. doi: 10.1146/annurev.pharmtox.47.120505.105214

Dasgupta, P., Rastogi, S., Pillai, S., Ordonez-Ercan, D., Morris, M., Haura, E., et al. (2006). Nicotine induces cell proliferation by beta-arrestin mediated activation of Src and Rb-Raf-1 pathways. J. Clin. Invest. 116, 2208-2217. doi: 10.1172/JCI28164

Dasgupta, P., Rizwani, W., Pillai, S., Kinkade, R., Kovacs, M., Rastogi, S., et al. (2009). Nicotine induces cell proliferation, invasion and epithelialmesenchymal transition in a variety of human cancer cell lines. Int. J. Cancer 124, 36-45. doi: 10.1002/ijc.23894

Descarries, L., Gisiger, V., and Steriade, M. (1997). Diffuse transmission by acetylcholine in the CNS. Prog. Neurobiol. 53, 603-625. doi: 10.1016/S03010082(97)00050-6

Di Resta, C., Ambrosi, P., Curia, G., and Becchetti, A. (2010). Effect of carbamazepine and oxcarbazepine on wild type and mutant neuronal nicotinic receptors linked to nocturnal frontal lobe epilepsy. Eur. J. Pharmacol. 643, 13-20. doi: 10.1016/j.ejphar.2010.05.063

Disney, A. A., Aoki, C., and Hawken, M. J. (2007). Gain modulation by nicotine in macaque V1. Neuron 56, 701-713. doi: 10.1016/j.neuron.2007.09.034

Egleton, R. D., Brown, K. C., and Dasgupta, P. (2008). Nicotinic acetylcholine receptors in cancer: multiple roles in proliferation and inhibition of apoptosis. Trends Pharmacol. Sci. 29, 151-158. doi: 10.1016/j.tips.2007.12.006

Faure, P., Tolu, S., Valverde, S., and Naudé, J. (2014). Role of nicotinic acetylcholine receptors in regulating dopamine neuron activity. Neuroscience 282, 86-100. doi: 10.1016/j.neuroscience.2014.05.040

Fu, X. W., Lindstrom, J., and Spindel, E. R. (2009). Nicotine activates and upregulates nicotinic acetylcholine receptors in bronchial epithelial cells. Am. J. Respir. Cell Mol. Biol. 41, 93-99. doi: 10.1165/rcmb.2008-0352OC

Gerde, P., Muggenburg, B. A., Stephens, T., Lewis, J. L., Pyon, K. H., and Dahl, A. R. (1998). A relevant dose of 4-(methylnitrosamino)-1-(3-pyridyl)-1-butanone is extensively metabolized and rapidly absorbed in the canine tracheal mucosa. Cancer Res. 58, 1417-1422.

Ghosh, D., Mishra, M. K., Das, S., Kaushik, D. K., and Basu, A. (2009). Tobacco carcinogen induces microglial activation and subsequent neuronal damage. J. Neurochem. 110, 1070-1081. doi: 10.1111/j.1471-4159.2009. 06203.x

Gioanni, Y., Rougeot, C., Clarke, P. B. S., Lepousè, C., Thierry, A. H., and Vidal, C. (1999). Nicotinic receptors in the rat prefrontal cortex: increase in glutamate release and facilitation of mediodorsal thalamo-cortical transmission. Eur. J. Neurosci. 11, 18-30. doi: 10.1046/j.1460-9568.1999.00403.x

Guo, J., Ibaragi, S., Zhu, T., Luo, L. Y., Hu, G. F., Huppi, P. S., et al. (2008). Nicotine promotes mammary tumor migration via a signaling cascade involving protein kinase C and CDC42. Cancer Res. 68, 473-8481. doi: 10.1158/0008-5472.CAN08-0131

Hecht, S. S., and Hoffmann, D. (1988). Tobacco-specific nitrosamines, an important group of carcinogens in tobacco and tobacco smoke. Carcinogenesis 9, 875-884. doi: 10.1093/carcin/9.6.875
Heeschen, C., Jang, J. J., Weis, M., Pathak, A., Kaji, S., Hu, R. S., et al. (2001). Nicotine stimulates angiogenesis and promotes tumor growth and atherosclerosis. Nat. Med. 7, 833-839. doi: 10.1038/89961

Hogg, R. C., and Bertrand, D. (2007). Partial agonists as therapeutic agents at neuronal nicotinic acetylcholine receptors. Biochem. Pharmacol. 73, 459-468. doi: 10.1016/j.bcp.2006.08.010

Improgo, M. R., Soll, L. G., Tapper, A. R., and Gardner, P. D. (2013). Nicotinic acetylcholine receptors mediate lung cancer growth. Front. Physiol. 4:251. doi: 10.3389/fphys.2013.00251

Jorquera, R., Castonguay, A., and Schuller, H. M. (1992). Placental transfer of 4-(methylnitrosamino)-1-(3-pyridyl)-1-butanone instilled intratracheally in Syrian golden hamsters. Cancer Res. 52, 3273-3280.

Jull, B. A., Plummer, H. K. III., and Schuller, H. M. (2001). Nicotinic receptormediated activation by the tobacco-specific nitrosamine NNK of a Raf-1/MAP kinase pathway, resulting in phosphorylation of c-myc in human small cell lung carcinoma cells and pulmonary neuroendocrine cells. J. Cancer Res. Clin. Oncol. $127,707-717$.

Kawai, H., and Berg, D. K. (2001). Nicotinic acetylcholine receptors containing the $\alpha 7$ subunits on rat cortical neurons do not undergo long lasting inactivation even when upregulated by chronic nicotine exposure. J. Neurochem. 78, 1367-1378. doi: 10.1046/j.1471-4159.2001.00526.x

Lambe, E. K., Picciotto, M. R., and Aghajanian, G. K. (2003). Nicotine induces glutamate release from thalamocortical terminals in prefrontal cortex. Neuropsychopharmacology 28, 216-225. doi: 10.1038/sj.npp.1300032

Magleby, K. L., and Stevens, C. F. (1972). The effect of voltage on the time course of end-plate currents. J. Physiol. 223, 151-171. doi: 10.1113/jphysiol.1972.sp009839

Maneckjee, R., and Minna, J. D. (1990). Opioid and nicotine receptors affect growth regulation of human lung cancer cell lines. Proc. Natl. Acad. Sci. U.S.A. 87, 3294-3298. doi: 10.1073/pnas.87.9.3294

McNerney, M. E., Pardi, D., Pugh, P. C., Nai, Q., and Margiotta, J. F. (2000). Expression and channel properties of alpha-bungarotoxin-sensitive acetylcholine receptors on chick ciliary and choroid neurons. J. Neurophysiol. $84,1314-1329$.

Nelson, M. E., Kuryatov, A., Choi, C. H., Zhou, Y., and Lindstrom, J. (2003). Alternate stoichiometries of alpha4beta2 nicotinic acetylcholine receptors. Mol. Pharmacol. 63, 332-341. doi: 10.1124/mol.63.2.332

Nunes-Alves, A., Nery, A. A., and Ulrich, H. (2012). Tobacco nitrosamine Nnitrosonornicotine as inhibitor of neuronal nicotinic acetylcholine receptors. J. Mol. Neurosci. 49, 52-61. doi: 10.1007/s12031-012-9859-5

Paleari, L., Catassi, A., Ciarlo, M., Cavalieri, Z., Bruzzo, C., Servent, D., et al. (2008). Role of alpha7-nicotinic acetylcholine receptor in human non-small cell lung cancer proliferation. Cell Prolif. 41, 936-959. doi: 10.1111/j.13652184.2008.00566.x

Paleari, S., Sessa, F., Catassi, A., Servent, D., Mourier, G., Doria-Miglietta, G., et al. (2009). Inhibition of non-neuronal alpha7-nicotinic receptor reduces tumorigenicity in A459 NSCLC xenografts. Int. J. Cancer 125, 199-211. doi: 10.1002/ijc. 24299

Palma, E., Bertrand, S., Binzoni, T., and Bertrand, D. (1996). Homomeric neuronal nicotinic $\alpha 7$ receptors present five putative high affinity binding sites for the toxin MLA. J. Physiol. 491, 151-61. doi: 10.1113/jphysiol.1996.sp021203

Paradiso, K. G., and Steinbach, J. H. (2003). Nicotine is highly effective at producing desensitization of rat $\alpha 4 \beta 2$ neuronal nicotinic receptors. J. Physiol. 553, 857-871. doi: 10.1113/jphysiol.2003.053447

Pfeifer, G. P., Denissenko, M. F., Olivier, M., Tretyakova, N., Hecht, S. S., and Hainaut, P. (2002). Tobacco smoke carcinogens, DNA damage and p53 mutations in smoking-associated cancers. Oncogene 21, 7435-7451. doi: 10.1038/sj.onc. 1205803

Poorthuis, R. B., Bloem, B., Schak, B., Wester, J., de Kock, C. P., and Mansvelder, H. D. (2012). Layer-specific modulation of the prefrontal cortex by nicotinic acetylcholine receptors. Cereb. Cortex 23, 148-161. doi: 10.1093/cercor/bhr390

Porter, J. T., Cauli, B., Tsuzuki, K., Lambolez, B., Rossier, J., and Audinat, E. (1999). Selective excitation of subtypes of neocortical interneurons by nicotinic receptors. J. Neurosci. 19, 5228-5235.

Rollema, H., Chambers, L. K., Coe, J. W., Glowa, J., Hurst, R. S., Lebel, L. A., et al. (2007). Pharmacological profile of the $\alpha 4 \beta 2$ nicotinic acetylcholine receptor partial agonist varenicline, an effective smoking cessation aid. Neuropharmacology 52, 985-994. doi: 10.1016/j.neuropharm.2006.10.016 
Russell, M. A. H., Jarvis, M., Iyer, R., and Feyerabend, C. (1980). Relation of nicotine yield of cigarettes to blood nicotine concentrations in smokers. $\mathrm{Br}$. Med. J. 280, 972-976. doi: 10.1136/bmj.280.6219.972

Schaal, C., and Chellappan, S. P. (2014). Nicotine-mediated cell proliferation and tumor progression in smoking-related cancers. Mol. Cancer Res. 12, 14-23. doi: 10.1158/1541-7786.MCR-13-0541

Schuller, H. M. (1989). Cell type specific, receptor mediated modulation of growth kinetics in human lung cancer cell lines by nicotine and tobaccorelated nitrosamines. Biochem. Pharmacol. 38, 3439-3442. doi: 10.1016/00062952(89)90112-3

Schuller, H. M. (2007). Nitrosamines as nicotinic receptor ligands. Life Sci. 80, 2274-2280. doi: 10.1016/j.lfs.2007.03.006

Schuller, H. M. (2009). Is cancer triggered by altered signaling of nicotinic acetylcholine receptors? Nat. Rev. Cancer 9, 195-205. doi: 10.1038/ nrc2590

Schuller, H. M., and Orloff, M. (1998). Tobacco-specific carcinogenic nitrosamines. Ligands for nicotinic acetylcholine receptors in human lung cancer cells. Biochem. Pharmacol. 55, 1377-1384. doi: 10.1016/S0006-2952(97)00651-5

Schuller, H. M., Tithof, P. K., Williams, M., and Plummer, H. III. (1999). The tobacco-specific carcinogen 4-(methylnitrosamino)-1-(3-pyridyl)-1-butanone is a beta-adrenergic agonist and stimulates DNA synthesis in lung adenocarcinoma via beta-adrenergic receptor-mediated release of arachidonic acid. Cancer Res. 59, 4510-4515.

Song, P., Sekhon, H. S., Fu, X. W., Maier, M., Jia, Y., Duan, J., et al. (2008). Activated cholinergic signaling provides a target in squamous cell lung carcinoma. Cancer Res. 68, 4693-4700. doi: 10.1158/0008-5472.CAN-08-0183

Tsurutani, J., Sianna Castillo, S., Brognard, J., Granville, C. A., Zhang, C., Gills, J. J., et al. (2005). Tobacco components stimulate Akt-dependent proliferation and NFKB-dependent survival in lung cancer cells. Carcinogenesis 26, 1182-1195. doi: $10.1093 /$ carcin/bgi072
Vidal, C., and Changeux, J. P. (1993). Nicotinic and muscarinic modulations of excitatory synaptic transmission in the rat prefrontal cortex. Neuroscience 56, 23-32. doi: 10.1016/0306-4522(93)90558-W

Wessler, I., and Kirkpatrick, C. J. (2008). Acetylcholine beyond neurons: the nonneuronal cholinergic system in humans. Br. J. Pharmacol. 154, 1558-1571. doi: 10.1038/bjp.2008.185

West, K. A., Brognard, J., Clark, A. S., Linnoila, I. R., Yang, X., Swain, S. M., et al. (2003). Rapid Akt activation by nicotine and a tobacco carcinogen modulates the phenotype of normal human airway epithelial cells. J. Clin. Invest. 111, 81-90. doi: 10.1172/JCI200316147

Xiang, Z., Huguenard, J. R., and Prince, D. A. (1998). Cholinergic switching within neocortical inhibitory networks. Science 281, 985-988. doi: 10.1126/science.281.5379.985

Zoli, M., Pistillo, F., and Gotti, C. (2015). Diversity of native nicotinic receptor subtypes in mammalian brain. Neuropharmacology 96, 302-311. doi: 10.1016/j.neuropharm.2014.11.003

Zolles, G., Wagner, E., Lampert, A., and Sutor, B. (2009). Functional expression of nicotinic acetylcholine receptors in rat neocortical layer V. Cereb. Cortex 19, 1079-1091. doi: 10.1093/cercor/bhn158

Conflict of Interest Statement: The authors declare that the research was conducted in the absence of any commercial or financial relationships that could be construed as a potential conflict of interest.

Copyright (C) 2015 Brusco, Ambrosi, Meneghini and Becchetti. This is an open-access article distributed under the terms of the Creative Commons Attribution License (CC $B Y)$. The use, distribution or reproduction in other forums is permitted, provided the original author(s) or licensor are credited and that the original publication in this journal is cited, in accordance with accepted academic practice. No use, distribution or reproduction is permitted which does not comply with these terms. 